\title{
SOCIAL SUSTAINABLE DEVELOPMENT OR SUSTAINABLE SOCIAL DEVELOPMENT - TWO SIDES OF THE SAME COIN? THE STRUCTURE OF SOCIAL JUSTICE AS A NORMATIVE BASIS FOR THE SOCIAL DIMENSION OF SUSTAINABILITY
}

\author{
THILO J. KETSCHAU \\ Department of Business Education and Human Resource Development, Georg-August-University Göttingen.
}

\begin{abstract}
The development of the social dimension of sustainability is discussed in the terminological dualism, which is essential to the concept itself: Sustainable social development (SuSoDe), addressing the idea of a socially sustainable society, and social sustainable development (SoSuDe), regarding the implementation of sustainability in the structure of society. Thereby, the precarious interdependency of both concepts becomes obvious, revealing the necessity of a multidimensional model of social justice as a normative foundation. This model is described in its functional idea as a merging point for the dualism of the development of the social dimension of sustainability and therefore as a framework for social sustainability theory.

Keywords: normative, reflexive-dialectical approach, social sustainability, social justice, social development.
\end{abstract}

\section{INTRODUCTION}

If sustainable development is understood as a process of transformation of the economy, it is, in consequence, also a transformation of society. Thereby, the social dimension of sustainable development seems essential for discussions on sustainability. But compared with the economic and environmental dimension of sustainability, social sustainability seems to be quite less addressed in sustainability research [1-3]. According to the assumption that the three dimensions are interdependent [4-7], this deficit may potentially hamper sustainable development in total.

The discussion of objectives for the social dimension of sustainable development leads to the question of its normative configuration. Regarding the social dimension, sustainable development may be specified in two ways: sustainable social development (SuSoDe) and social sustainable development ( $\mathrm{SoSuDe})$. The first may be understood as the objective that social development has to be based on norms which are in line with the idea of sustainability. The second may be understood as the condition of sustainable development being socially acceptable. Both terms seem to be different perspectives, but they might share the same normative basis: the idea of social justice. Without a normative basis, social sustainability and thereby sustainable development are, in last consequence, empty terms which may be used arbitrarily.

With a reflexive-dialectical approach, these two aspects are designed to show the dualism of the social dimension of sustainable development (DSD). Based on this, a multidimensional model of social justice is proposed as a normative basis for the realization of these aspects, including aspects of different social justice theories. The implications of these reflections will be valuable for the identification of barriers and perspectives for sustainable development in the capitalistic social order. The research questions are, therefore: How does the discourse of 
the concepts of SuSoDe and SoSuDe constitute the DSD and what are the implications? Which kind of model of social justice can be used as a norm for both concepts of the dualism and therefore for social sustainability itself?

\section{THE SOCIAL DIMENSION OF SUSTAINABLE DEVELOPMENT}

Sustainable development is generically defined as the principle of ensuring that the actions of present generations "do not limit the range of economic, social, and environmental options open to future generations" [8]. The social aspects of sustainable development are subsumed in the term of social sustainability, whose meaning currently seems to be beyond consensus and concreteness. Often it is indirectly described by related ideas, e.g. justice or social stability $[2,5]$ or it is shortened to the proposition of measures, indicators, and political objectives, e.g. poverty reduction $[6,9,10]$. Such definitions are too vague or lack theoretical foundation; others are too complex to deduce a concrete idea of social sustainability (e.g. [11]). So the need for a working definition is obvious.

Social sustainability can be defined as the condition of a society where social tensions do not escalate but are solved in a peaceful way. This should result in social peace, just chances for individual self-development and maximal freedom of action [5]. Furthermore, it inherits the solving of distribution problems between social classes, regions, genders and generations $[1,2]$. As far as the development of social sustainability is operationalized by particular objectives [5], it can be understood as a condition of a society which is achieved by these objectives. Therefore, the effect of these objectives has to appear by tendency permanently in social life and social structure. Those objectives may be (exemplary according to $[5,19]$ ) social stability, individual freedom, social justice, equal opportunities and ensuring and improving ecological, economic and social performance.

Political agendas mostly ignore the role of elite or above-average privileged social groups and individuals for sustainable development. But in the discussion of social issues these elites have to be addressed at least theoretically. In a very generic understanding, which is sufficient for the deliberations of this paper, two distinctions are made. The term of high-privileged or elites refers to groups and individuals of society, whose social and economic opportunities are recognized to be significant above-average in relation to the opportunities of the majority of society. Contrary, the part of society which is not covered by this definition is termed non-elites. Those groups and individuals, whose social and economic opportunities are recognized to be significant below-average in relation to the opportunities of the majority of society, are termed as low-privileged. In this definitions logic, low-privileged groups and individuals are also part of the non-elite. These two basic distinctions, between elite and nonelite and high-privileged and low-privileged, are needed for the discussion of a social development as is sustainable development. Otherwise, the discourse would be shapeless and questions of social justice could not be addressed.

\section{SUSTAINABLE SOCIAL DEVELOPMENT}

SuSoDe is the aspect of DSD, which refers to the development of a socially sustainable society. According to the findings of the Club of Rome [12-14], indicating the threat of overextension of ecological and social systems if sustainable development is ignored, the analogue social transformation is especially urgent for permanence and resilience of society. The realization of SuSoDe is ideally in the responsibility of the majority of social actors, especially political and economic institutions and social organizations. An orientation for these actors has to be the sustainability idea in general and social objectives, defined by politics and 
science, in particular. A scientific operationalization of objectives for the social dimension of sustainable development is provided by Kopfmüller et al. [15]. With the primacy of preservation of individual opportunities for development and action the following subordinated aspects are defined: (1) participation in societal decision-making processes, (2) preservation of social resources, (3) equality of opportunities in education, job and information and (4) preservation of cultural diversity and cultural heritage.

As target criteria of social and sustainable development, these aspects are to be assessed differently. Aspect (1) is foundation and premise of democracy and thereby principally established in the political life of Western nations. The implementation beyond this is dependent on the further political development of non-democratic states. Aspect (2) can be derived from the idea of resource conservation as the core of the sustainability idea. This remains the vaguest and thereby potentially most likely interpretable aspect, and questions of the distribution of those resources have to be addressed in the further discussion. Aspect (3) is more concrete even if the term equality of opportunities leaves room for interpretation. So it remains open, therefore, whether a system of education generally accessible to all, is sufficient, or if questions of heterogeneous entrance criteria, caused by social background and cognitive abilities, have to be discussed, and with which consequences. Aspect (4) is to be criticized with regard to its obvious premise that culture is absolutely worthy of being preserved. Even beyond poststructuralist reflections, it seems possible, that cultural aspects may be divergent to the sustainability idea. Examples are the traditional whale hunting in Japan or the fetish-character of automobiles in some western cultures. So culture must be an object of transformation, not of conservation. Furthermore, it has to be considered that culture is also a medium for social relations of force as a result of traditions (see the works of the Frankfurt School, for example, [16]), which may not be in line with the other aspects of SuSoDe.

\section{SOCIAL SUSTAINABLE DEVELOPMENT}

SoSuDe refers to the problem of a socially acceptable design of sustainable development. The assumption, that sustainability may not be socially compatible, seems paradoxical in the first place. But, on one hand, conflicts between the target dimensions of sustainability may be resolved to the disadvantage of social aspects; on the other hand, different foundations of social sustainability can lead to different shades of its social development. Both assumptions and the following discussion are still based on the premise, that social evolution should equally serve the benefit of all members of society, meaning the development and preservation of wealth to the extent possible as well as the minimization of relations of force.

The main question concerning the social compatibility of sustainable development concerns the distribution of the related costs. These costs consist of product costs, resulting from the higher expenditure on sustainably produced products of any kind compared to nonsustainable products. Examples are foods which are offered both in a conventional kind and in a kind produced in a particular ecological way for a relatively higher price [17]. Furthermore, there are redistribution costs which, in perspective, will be a problem for the wealthier nations because of the fact, that their wealth is based essentially on the exploitation of poorer nations [18]. Understanding sustainability as a global concept, this exploitation has to be reduced and stopped. Additionally, it has been ascertained, that the living standard of Western nations is not suitable as a global reference $[12,13]$. Both circumstances allow the conclusion that this living standard has to be reduced, and even if these painful assumptions are rarely concretized, they are the logical conclusion of the sustainability idea and finite resources. 
From a social point of view, the question of the assumption of these costs arises. There are two general possibilities: assumption by the economic elites, for example, the company owners, or by the non-elites, which are mostly employed workers and the majority of consumers. For the social development, this is closely connected to the question of the scope of the social transformation connected to sustainable development. While the assumption of these costs by the non-elites in the sense of a primary capitalistic economic and social order would not burden the enterprises and would not question property-bound social hierarchies, the assumption of costs by the elites and thereby the enterprises would potentially hamper economic development and is not in line with a neoliberal understanding of society. So, enterprises may be beneficiaries of sustainable development by the commercialization of sustainable products and by passing on the additional costs for these products to the consumer. Or enterprises may be made responsible for the eradication of the negative effects of their actions, which inherits the danger of their unprofitability and thereby provokes a decline in overall economic performance. Which mode of cost allocation is preferable should be assessed based on a normative foundation of social sustainability which is discussed below.

By these considerations, a conflict between the social and economic dimension of sustainability becomes obvious, which manifests as inner-societal class antagonism. Within a capitalistic constituted economy, economic sustainability implies that the imperative of function of the economic system must not be endangered. The relevant protagonists on this side are employers and business associations. Social sustainability implies the other side of this antagonism, with the imperative of social freedom, represented by unions and NGOs, which are committed to the interests of non-elites [11]. This conflict is present only as far as capitalism is the primacy of economic order. This given, consequences of this conflict are only relevant in the context of social sustainability since the existence and position of the elites are not jeopardized by social developments. It remains a one-direction-conflict. In this context, it remains to be discussed to which extent economic sustainability is conceivable outside capitalism, or how far, in turn, social sustainability can be founded and structured without substantial social transformations. This discussion can result in considerations to what extent, ultimately, social inequalities are degraded or strengthened, and thus accepted or even understood as a constituent feature of the social order. As a result, the relations of force in modern societies, impressively documented by the work of the critical theorists of the Frankfurt School (for example [19, 20]), have to be renewed or dissolved. The final question is: To which degree has sustainable development to be social?

The interdependency of the described dualism, SuSoDe and SoSuDe, can be located in the perspective of sustainable development. On one hand, if social development is to be future-oriented, it must be in line with the principles of sustainability, otherwise it will fail due to the challenges predicted by the Club of Rome $[12,13]$. On the other hand, if sustainable development should be anchored in society, there is a need of a normative foundation of it which elevates it above an economic or political fashion and enables every member of society to realize it as a development without any alternative. A society, which is still based on economic relations of force and dependency, may not achieve these states. As long as economic unconscionability is an essential regulating principle, sustainability will be an issue of profitability.

\section{MULTIDIMENSIONAL SOCIAL JUSTICE AS A NORMATIVE BASIS}

In a most generic way, social justice can be defined as the state of a society when the distribution of rights, opportunities and resources can be rated as just. A precise idea of what is just 
and what not is thereby not clear and remains an issue of political and philosophical discussion [21].

The linking of sustainability and justice has been addressed scientifically in several ways. The approach of Ekardt [22] aims at an identity of justice and sustainability. Also for Grunwald and Kopfmüller [2] social sustainability is identical with the just distribution of social basic goods, like health, food and political rights. However, there is no justification for the restriction to basic goods. Overall, this approach is too short and too vague.

Social justice as an attribute of social sustainability is called by different political agendas, first of all, the Brundtland-Report [8]. Also, the basis of the sustainability strategy of the German Federal Parliament, the report of the Enquete commission [5], addresses social justice as a component of sustainable development. However, these documents dispense with a more precise theoretical differentiation of the required concept of justice. Mostly, they are limited to the designation of poverty control or the emphasis on solidarity and the welfare state.

The purpose of a model of social justice, serving as a normative foundation of the idea of social sustainability, is the creation of a reference framework, which allows the distribution of resources, wealth, and chances for self-fulfilment among all members of society according to an objective, reasonable, rational and moral modus. It is important to ensure that no overreaching and no discrimination are created amongst the members of a society and the resulting societal structure is permanently acceptable for all. Several aspects of justice are relevant.

The formulation of sustainability as an intergenerational concept is already evident in the basic definition of the Brundtland Commission which aims at the optimization of the living conditions of future generations [8]. This essentially means that every generation has to solve their problems instead of leaving them for future generations and avoids actions, which may in the present be beneficiary but are likely to be problematic in the future. The SuSoDe-aspect of DSD addresses this intention. Also, since sustainable development is a process which will most probably last for several generations, intergenerational justice is an issue in the perspective of SoSuDe. Thereby a time-related dimension for a social justice model is already postulated by defining the situation of future generations as a reference for sustainable action. The corresponding dimension of the model is referred to as generation, given this terminological reference.

In the emphasis on individual possibilities of development (for example [5]), the question of the shape of society as an environment for the individual arises. How must the structure and the order of a society be, in which each individual has a maximum of these possibilities? This makes the second dimension of the social justice model apparent. The need for differentiation in the interests of individuals and society as a whole as dichotomous categories of justice was formulated by Ketschau [23] as a reference for specification of the social sustainability theory. This was reasoned with a possible antagonism between the interests of individuals and the welfare of society as a whole. This second dimension is named as perspective.

If the issue of the betterment of socially disadvantaged people is addressed, as is the case with all political agendas devoted to sustainability, the question of a redistribution of limited resources and consequently the consideration of social elites cannot be ignored. The antagonism of high-privileged and low-privileged is the basis for the third dimension of the social justice model. For the close relation to the issue of differences between social classes, it is named class. The poles of over-privileged and under-privileged inherit different problems. 
Under-privileged individuals may have relatively little participation in market transactions because of insufficient financial resources and may, therefore, be left outside the focus of economic considerations [24]. On the other side, over-privileged individuals are to some point the beneficiaries and sponsors of the structures causing these social disadvantages. This antagonism was revealed and discussed especially by works of critical theory (for example $[16,19])$ and manifests by the rising gap between rich and poor $[25,26]$.

This results in three functional dimensions of social justice, each of which is structured as a dichotomy. The dimension generation encompasses the intergenerational as well as the intragenerational aspects of social justice. The dimension perspective covers both the individual as well as the society as a whole for considerations on justice. The dimension class considers the high-privileged as well as the low-privileged members of society equally.

If a holistic understanding of social justice should be established, as it seems necessary for the idea of social sustainability, every aspect of every dimension has to be addressed with a theory. This does not imply that all dimensions have to be based on the same theory of social justice. Due to the heterogeneity of the dimensions, this seems unrealistic and provokes a simplification that would not be adequate to the complexity of societal structures.

Distributive justice is the most generic of the model-relevant theories. According to Kersting [27], distributive justice tries to solve the justice problem by defining what has to be distributed by whom towards whom and in which way. The ascertainment of these variables remains a philosophical and political problem. The basic formula of distributive justice is the scheme of distribution of a social relevant good by agents of distribution towards recipients of distribution based on a criterion of distribution. Agents as well as recipients may be individuals or institutions. Goods may be diverse material or immaterial quantities, which mostly refers to wealth and education [27]. The criterion as the modus operandi of distribution is based on the regulation of the justice formula, which is the premise of this justice and therefore the substance of theoretical considerations. So, by distributive justice, the dimension class can be concretized, as well as the aspect society of the dimension perspective.

The same applies to Rawls theory of justice. His basic question is that of a just societal order. How does a society have to be structured so that all members are willing to accept this order, regardless of the social role and position they might inherit [28]? This may be thought from the perspective of the individual, but primarily addresses questions of the intra-social distribution. With the premise of an ideologically neutral state, two paragraphs are postulated. First, the right to the most comprehensive system of fundamental freedoms without endangering the basic freedoms of others. Second, the design of inequalities under the premise, that everyone benefits from them and that they are bound to offices, which are generally accessible for everyone [28]. Thereby, Rawls addresses the relative relationships between members of the society and especially the question of an acceptable extent of asymmetric distribution of wealth, which is essential for the dimension class and the aspect society of the dimension perspective.

Also the capabilities approach focuses its understanding of social justice on a central question: What capabilities does a person need to achieve a successful life [29]? It thereby addresses the aspect individual of the perspective dimension. This approach is connected closely to the idea of personal freedom because social justice with regard to equality of opportunity and capability is essential for the individual exercise of freedom [30]. In theory, no quantitative definition of capabilities is available. As a result, it cannot be stated what minimum level of capabilities a society needs to be just [30]. Sens theory addresses thereby 
the individual aspect of the model. Since capabilities are different for individuals [31] the adaptation of the approach to a view on society as a whole through the social sustainability concept is limited. As far as capabilities have to be considered as finite quantities within a society, the question of distribution among the members of a society arises. Additionally, subjective preconditions for capabilities have to be assumed as a result of social disparity, so individual demands for self-fulfilment are already a result of socialization and in consequence a product of societal hierarchies, orders and constraints [23].

The inadequacy of the restriction to one theory is exemplified by the dimension perspective. Rawls approach is too egalitarian and does not consider the uniqueness of every individual. Sens approach, on the other hand, is hardly adequate to reflect societal structures in their entirety and therefore can be potentially used for substantiation of elites by its neglect of the limitedness of the quantities of capabilities. So, ignoring the question of how different capabilities should be and how far objective criteria are needed for their assessment, it is not possible to discuss whether the capabilities of the high-privileged part of society are adequate and just and therefore acceptable or not. Approaches focused on individuals tend to ignore the relations of society, that is, the relations of the manifestations of the power of disposition over relevant resources between the members of society.

The discussion of the question of the distribution of costs of sustainable development, related to the aspect of SoSuDe, needs the perspective of distributive justice. The old question of how to distribute the prosperity of a society is now specified: How is the effort of the society's future viability distributed in a just way? A logical answer would be to leave these costs to those elements of society, which have benefitted most from the factors causing the need of sustainable development and have therefore supported these factors. In the capitalist society, those are the enterprise shareholders and the economic elites, the biggest winners of the consumption binge in the Western nations. On the other hand, sustainability must not serve as a marketing tool for increasing business profits, and costs of sustainable development must not be passed on to the consumers via the markets. This would be an externalization of these costs towards the non-elites. Therefore, a simple and an unspecified reference to the just distribution of social goods in the context of sustainability (such as [2]) is not enough because the justness of sustainable development is shown by a consideration of its cost-benefit distribution.

A multidimensional model of social justice raises its own challenges. As a result of possible conflicts between the both poles of every dimension, the problem of prioritizing one of these poles arises. In the dimension perspective, divergences may arise with the question of priority for resource distribution, as far as the demands of one or more individuals collide with each other. In this case, a hierarchy of demands may be defined by two imperatives. First, opportunities for self-fulfilment for an individual must not reduce the opportunities for a group. Second, in a case of colliding individual interests, the possible impairment of the opportunities of subject A must not be higher than the benefit for the opportunities of subject $\mathrm{B}$, if the conflict is resolved in the interest of subject $\mathrm{B}$, and vice versa. Similarly, the question is whether the focus on the individual is an unconditional primacy of social justice, and it would be negated here. From the simple logic that a society is always a set of individuals, their interests as a community must be placed before the interests of an individual. Two questions remain to be clarified. For which cases and in reference to what criteria may the interests of an individual be more important than those of a group? And how are the societal benefit and individual impairment of opportunities assessed and compared? 


\section{SYNOPSIS AND CONCLUSION}

The development of social sustainability is not a one-dimensional process, which might be realized by the operationalization and implementation of sustainability criteria. The way of social transformation must be considered equally. This dualism was specified by the aspects SuSoDe and SoSuDe. In spite of their semantic similarity, they appear as different complexes. They are based on different theories and their theoretical relation to the idea of sustainable is different. Whether SuSoDe is derived directly from the operationalized objectives of social sustainability, SoSuDe is based on critical considerations on the distribution of costs and benefits of sustainable development and on the constitution of societal relations of force. As a condition for achieving the goal of a socially sustainable society, both aspects find a similarity, as well as in the possibility of the foundation with a model of social justice, which has been functionally outlined as a multidimensional variant. This foundation also leads to an antagonistic relationship between social sustainability and the capitalist economic order, which is shared by both aspects and whose exact intensities require a separate discussion.

For social sustainability as the subject of economic and cultural sciences, recognition of a primacy of social justice would mean that the economic guiding principle would no longer be the question of the best possible sustainable economic growth. It would be the question of the justest solution, as far as, on this theoretical level, an identity of social justice and social sustainability would be assumed. And even if a primacy of social justice is questioned, the search for the socially just moment must at least be thought through, if the complex of the social and thus one of the dimensions of sustainability should not be negated.

The dichotomous dimensions of the proposed model of social justice are very simple in their present state. It appears sufficient for the apprehension of aspects, which are relevant for a social justice theory which is adequate to the requirements of the further theoretical analysis and foundation of social sustainability. For a further development of the content and the subsequent empirical apprehension, however, it seems necessary to assume a continuum between the two respective dimension poles, which would be discussed in following works for the individual dimensions. The content-related design of the model is essentially based on established justice theories. The challenge here lies in their mutual integration and the adaptation to the concept of social sustainability. As already pointed out by previous works [23], the goal must be the operationalisability of the dimensions in order to be able to deduce the parameters for empirical applicability. This is necessary for the development of a construct of social sustainability, which can be used for the evaluation of sustainable development. On a philosophical level, it is necessary to develop imperatives, which are clearly applicable to their respective dimensions and which are at the same time conflict-free to other dimensions. Because even with all practical considerations and problems, the standards for decisions and considerations have to be recognizable and reasonable.

In addition to the further development of the multidimensional model of justice, other desiderata are evident. The discussion of DSD shows not only the persistent need for a holistic and specific theory of social sustainability. It offers the possibility to link it with approaches of critical theory in order to gain a societal critical moment, which can provide the necessary impulses for a social transformation through and for sustainable development. This would make it clear in the discussion of the social dimension of sustainable development that capitalism, and especially its neoliberal shape, are by no means a sacrosanct natural order, but only one of several discernible economic orders and their facets. 
If social justice is accepted as a normative basis for sustainable development, two questions arise. First, how far the existing capitalist economic order can be regarded as socially just; a question which has been discussed for decades without consensus (see e.g. [32]). And secondly, whether there are other ideas and concepts to complement or even offer alternatives to social justice, which may allow a different view on social sustainability, such as the currently dominant neoliberalism or conservative-religious world views.

Without considering the different aspects of the development of social sustainability, sustainable development will fail. A holistic consideration seems possible if social justice is designated as a normative primacy of social sustainability. This requires a multi-dimensional understanding of justice, which can cover and integrate all the aspects contained in the complex of social sustainability. Ultimately, however, every theory and model of social justice has to face the same barrier that ethics and morality have always been confronted with: the human egoism. Finally, to get to the heart of it with the words of Wolfgang Kersting $([11,27]$ translation by the author): "we are closer to ourselves than to anyone else, so it is harder for altruism than for egoism".

\section{REFERENCES}

[1] Pufé, I., Nachhaltigkeit, 2nd edn., UVK Verlag: Konstanz/Munich, 2014.

[2] Grunwald, A. \& Kopfmüller, J., Nachhaltigkeit, 2nd edn., Campus Studium: Frankfurt a.M., 2012.

[3] Trainer, T., Social responsibility: the most important, and neglected, problem of all? Int. J. Soc. Econ, 32, pp. 682-703, 2005. https://doi.org/10.1108/03068290510608200

[4] Elkington, J., Cannibals with Forks, Capstone Publishing: Oxford, UK, 1999.

[5] Enquete-Kommission, "Schutz des Menschen und der Umwelt" Konzept Nachhaltigkeit. Vom Leitbild zur Umsetzung " des 12. Deutschen Bundestages, Bonn, Germany, 1998.

[6] Enquete-Kommission, "Wachstum, Wohlstand, Lebensqualität - Wege zu nachhaltigem Wirtschaften und gesellschaftlichem Fortschritt in der Sozialen Marktwirtschaft" des 17. Deutschen Bundestages, Bonn, Germany, 2013.

[7] UNCSD, Indicators of Sustainable Development. Framework and Methodologies, New York, 1996.

[8] UN World Commission on Environment and Development, Our Common Future: From One Earth to One World. An Overview, Oxford University Press: Oxford, UK, 1987.

[9] United Nations, Agenda 21, available at http://www.unep.org/Documents.Multilingual/ Default.asp?documentid=52, 1993 (accessed 17 August 2016).

[10] United Nations, The future we want. Resolution 66/288, 2012.

[11] Opielka, M., Soziale Nachhaltigkeit aus soziologischer Sicht. Soziologie, 45. Jg., 1, pp. 33-46, 2016.

[12] Meadows, D., Meadows, D., Randers, J. \& Behrens, W.W., III, The Limits to Growth, Universe Books: New York, 1972.

[13] Meadows, D., Meadows, D. \& Randers, J., Beyond the Limits. Global Collapse or a Sustainable Future, Earthscan Publications: London, 1992.

[14] Meadows, D., Meadows, D. \& Randers, J., Limits to Growth: The 30-Year Update, Chelsea Green: White River Junction, VT, 2004.

[15] Kopfmüller, J., Brandl, V., Jörissen, J., Paetau, M., Banse, G., Coenen, R. \& Grunwald, A., Nachhaltige Entwicklung integrativ betrachtet - Konstitutive Elemente, Regeln, Indikatoren, Edition Sigma: Berlin, 2012. 
[16] Horkheimer, M., Traditionelle und kritische Theorie, Gesammelte Schriften, Band 4, Fischer: Frankfurt am Main, 1988.

[17] Haubach, C. \& Held, B., Ist ökologischer Konsum teurer? Statistisches Bundesamt: Wiesbaden, 2015.

[18] Hartman, E., Wie viele Sklaven halten Sie? Campus Verlag: Frankfurt a.M. / New York, 2016.

[19] Horkheimer, M. \& Adorno, T. W., Dialektik der Aufklärung. Philosophische Fragmente, 21st edn., Fischer Verlag: Frankfurt a.M., 2013.

[20] Marcuse, H., The One-Dimensional Man. Studies in the Ideology of Advanced Industrial Society, Beacon Press: Boston, 1964.

[21] Cramme, C., Social Justice in the Global Age, Polity: Cambridge, UK, 2009.

[22] Ekardt, F., Theorie der Nachhaltigkeit. Rechtliche, ethische und politische Zugänge am Beispiel von Klimawandel, Ressourcenknappheit und Welthandel, Nomos: BadenBaden, 2016.

[23] Ketschau, T.J., Social Justice as a Link between Sustainability and Educational Sciences. Sustainability, 7, pp. 15754-15771, 2015. https://doi.org/10.3390/su71115754

[24] Winn, M. \& Kirchgeorg, M., Sustainability Marketing for the Poorest of the Poor. Bus. Strategy Environ, 15, pp. 171-184, 2006.

https://doi.org/10.1002/bse.523

[25] Oxfam International, An Economy for the 1\%. How privilege and power in the economy drive extreme inequality and how this can be stopped, available at https://www.oxfam. org/sites/www.oxfam.org/files/file_attachments/bp210-economy-one-percent-taxhavens-180116-en_0.pdf, 2016 (accessed 14 October 2016).

[26] Spannagel, D., Trotz Aufschwung: Einkommensungleichheit geht nicht zurück. WSIVerteilungsbericht 2015. In WSI-Mitteilungen, Band 68(2015), S. 622-629, 2015.

[27] Kersting, W., Theorien der Sozialen Gerechtigkeit, Metzler: Stuttgart, Germany, 2000. https://doi.org/10.1007/978-3-476-01668-3

[28] Rawls, J., A Theory of Justice, Revised edn., Harvard University Press: Cambridge, 1999.

[29] Sen, A., Commodities and Capabilities, North-Holland: New York, NY, 1985.

[30] Nussbaum, M.C., Capabilities as fundamental entitlements: Sen \& Social Justice. Fem. Econ., 9, pp. 33-59, 2003. https://doi.org/10.1080/1354570022000077926

[31] Sen, A., The Idea of Justice, Penguin Books: London, 2009.

[32] Fichtenbaum, R. \& Welty, G., Capitalist morality and social justice: a Marxist Critique. Forum Soc. Econ., 15, pp. 1-17, 1985.

https://doi.org/10.1007/BF02751474 